MATEC Web of Conferences 33, 07002 (2015)

DOI: $10.1051 /$ matecconf/ 20153307002

(C) Owned by the authors, published by EDP Sciences, 2015

\title{
Effect of Microstructures on Yield Strength in Hot-Stamped Steel Sheet
}

\author{
Shin-ichiro Tabata ${ }^{1, a}$, Kazuo Hikida ${ }^{1}$, Nobusato Kojima ${ }^{2}$ and Naomitsu Mizui ${ }^{3}$ \\ ${ }^{1}$ Sheet \& Coil Research Lab., Steel Research Laboratories, Nippon Steel \& Sumitomo Metal Corporation, 20-1 Shintomi Futtsu 293-8511, \\ Japan \\ ${ }^{2}$ Hirohata R \& D Lab., Technical Research \& Development Bureau, Nippon Steel \& Sumitomo Metal Corporation, 1 Fhji Hirohata 671-1188, \\ Japan \\ ${ }^{3}$ Railway Automotive \& Machinery Parts Research Lab., Steel Research Laboratories, Technical Research \& Development Bureau , Nippon \\ Steel \& Sumitomo Metal Corporation, 1-8 Fuso Amagasaki 660-0891, Japan
}

\begin{abstract}
For automotive structural parts, hot stamping is being increasingly used because of the need for both higher fuel efficiency and crashworthiness. The yield strength of hot-stamped steel sheet is lower than that of waterquenched steel sheet. The microstructure of hot-stamped low-carbon steel sheet comprises lath martensite and retained austenite. Due to the slow cooling rate below the martensite start temperature, the martensite formed by hot stamping is auto-tempered. To clarify the factor dominating the yield strength of the hot-stamped steel, the authors herein investigated the effect of microstructures on the yield strength with heat-treated specimens at various cooling rates and heating temperatures. Consequently, it was clarified that the yield strength of the auto-tempered low-carbon steel depends on grain, dislocation, solute carbon, carbide, and retained austenite. As far as the present experiment is concerned, the retained austenite is the most effective factor on the yield strength.
\end{abstract}

\section{Introduction}

Hot stamping is a promising process toward obtaining ultra-high strength steel sheet components with complex geometry. The formability of the sheets decreases with an increase in tensile strength. The advantage of the hot stamping process is small press load due to the high stamping temperature. Furthermore, hot stamping products possess high strength over $1500 \mathrm{MPa}$ and good shape accuracy without residual stress. In recent years, hot stamping for automotive structural parts is being increasingly used because of the need for both higher fuel efficiency and crashworthiness.

The microstructure of hot-stamped steel sheet comprises lath martensite and retained austenite. The lath martensite has substructures such as packet, block, and lath. The sizes of packet and block are linearly related to the prior austenite grain size [1-4]. The width of lath is approximately 0.2 um and almost constant [3]. The boundaries between packets and blocks are high-angle boundaries and those between laths are small-angle boundaries $[5,6]$. In low-carbon steel, the block is unclear [3]. Therefore, the packet size becomes the effective grain size of low-carbon martensitic steel. The retained austenite of low-carbon martensite was film-like and found in grain boundaries using transmission electron microscopy [7-9]. Carbon was concentrated in the retained austenite film up to 1.03 mass\% [10].
The martensitic steel is strengthened by solid solution, dislocation, precipitate dispersion, and grain refinement strengthening mechanisms. These strengthening mechanisms have been studied using various steels $[11$, 12]. To suppress aging at room temperature, $\mathrm{Fe}-\mathrm{Ni}$ or $\mathrm{Fe}-\mathrm{Ni}-\mathrm{C}$ alloys with subzero martensite start (Ms temperature) were studied $[13,14]$. As a result of mechanical test at $-196{ }^{\circ} \mathrm{C}$ subzero temperatures, the yield strength was proportional to the square root of solute carbon content.

In low-carbon steels, carbon diffusion cannot be suppressed during quenching because the Ms temperature is above room temperature [15]. The phenomenon is referred to as quench-tempering or auto-tempering. The evidence for carbon atom segregation to dislocations during quenching had been obtained by electrical resistivity measurement [16] and field ion/atom-probe microscopy [17]. In $0.18 \% \mathrm{C}$, almost $90 \%$ of $\mathrm{C}$ atoms were segregated to dislocations after quenching.

The low-carbon martensitic steel formed by hot stamping is auto-tempered due to slow cooling rate below the Ms temperature. The effect of auto-tempering on the hardness of hot-stamped boron-bearing steel has been studied by the experiments of various cooling rates [18, 19]. As a result, the cooling rate below Ms temperature significantly affected the hardness and carbide morphology, although a cooling rate was greater than the upper critical cooling rate.

\footnotetext{
${ }^{a}$ Corresponding author: tabata.4ga.shinichiro@jp.nssmc.com
} 
Herein, the authors investigated possible microstructural factors of the yield strength, and then estimated each contribution to clarify the factor dominating the yield strength of auto-tempered lath martensitic steel.

\section{Experinmental Procedures}

For hot stamping, 0.2 mass $\%$ C, 0.2 mass $\% \mathrm{Si}, 1.3$ mass $\% \mathrm{Mn}$, and B-bearing steel sheets are widely used. These steel sheets were heated at $900{ }^{\circ} \mathrm{C}, 1000{ }^{\circ} \mathrm{C}$, $1100{ }^{\circ} \mathrm{C}$, and $1200{ }^{\circ} \mathrm{C}$ and then quenched at $2330{ }^{\circ} \mathrm{C} / \mathrm{s}$ as shown in Figure 1(a). The steel sheets were heated at $900{ }^{\circ} \mathrm{C}$ and then cooled at various cooling rates. During cooling, the cooling rates are $80{ }^{\circ} \mathrm{C} / \mathrm{s}$ from $900{ }^{\circ} \mathrm{C}$ to $400{ }^{\circ} \mathrm{C}$ (Ms temperature), and up to $2330{ }^{\circ} \mathrm{C} / \mathrm{s}$ from $400{ }^{\circ} \mathrm{C}$ as shown in Figure 1(b). The cooling rate below $400{ }^{\circ} \mathrm{C}$ is defined as the secondary cooling rate. These heat treatments were conducted using the apparatus that comprises electric supply for resistance heating of specimens, cooling mechanism by jets out helium gas or water, and thermocouple controller. After heat treatment, some of the specimens were immersed into liquid $\mathrm{N}_{2}$ $\left(-196{ }^{\circ} \mathrm{C}\right)$ for $30 \mathrm{~min}$. All the specimens were subjected to tensile test, X-ray diffraction, and microscopic observation. To preserve room temperature aging, all the specimens were stored at $-15{ }^{\circ} \mathrm{C}$ until testing.

Tensile test was performed on the test piece ASTM$1 / 2$ with the gauge dimension of $32 \mathrm{~mm}$ length and 6.25 $\mathrm{mm}$ width. In this study, $0.2 \%$ proof stress $\left(\sigma_{0.2}\right)$ is defined as yield strength. Volume fraction of retained austenite $\left(V_{\gamma}\right)$, dislocation density $(\rho)$, and amount of solute carbon $\left(C_{\mathrm{s}}\right)$ were evaluated using X-ray diffraction. $\rho$ is calculated with following question [20]:

$$
\rho=14.4 \varepsilon^{2} / \mathrm{b}
$$

where $\varepsilon$ is the local strain obtained with WilliamsonHall's method [21] and $\mathrm{b}$ is the burgers vector of dislocation. The $C_{\mathrm{s}}$ was calculated from lattice parameter (a) with following equation [22]:

$$
a=\mathrm{a}_{0}+0.020 C_{s}
$$

where $\mathrm{a}_{0}$ is $2.8688 \AA$, measured in the normalized specimen.

Microstructure was observed by an optical microscope, a scanning electron microscope, and a transmission electron microscope. Prior austenite grain size was measured using the line intercept method on an optical photomicrograph. Retained austenite was observed by a scanning electron microscope with electron back scattering diffraction (EBSD). Carbide was observed by a transmission electron microscope with blank replica specimens. (a)

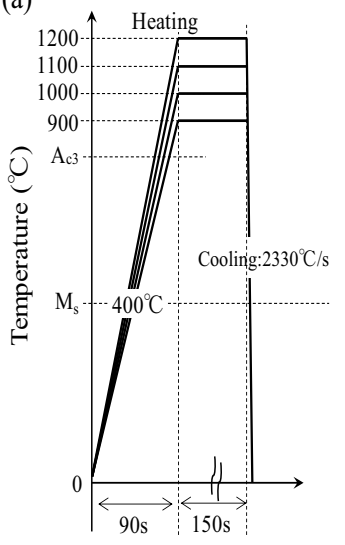

(b)

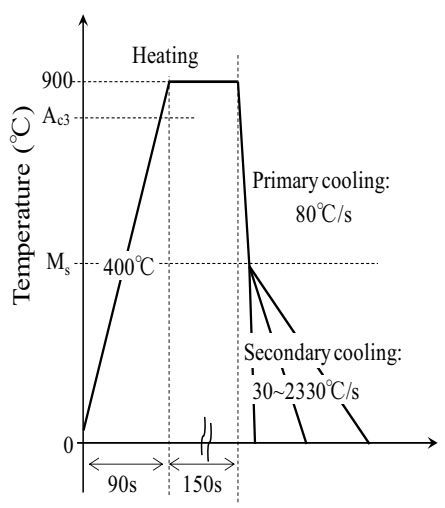

Figure 1. Heat-treatment condition changes of (a) heating temperature and (b) cooling rate below $400{ }^{\circ} \mathrm{C}$.

\section{Results}

\subsection{Heating temperature}

The effect of heating temperature on $0.2 \%$ proof stress and prior austenite grain size in the steel sheets cooled at various temperatures is shown in Figure 2. With an increase in heating temperature, the $0.2 \%$ proof stress decreased, and the prior austenite grain size increased.
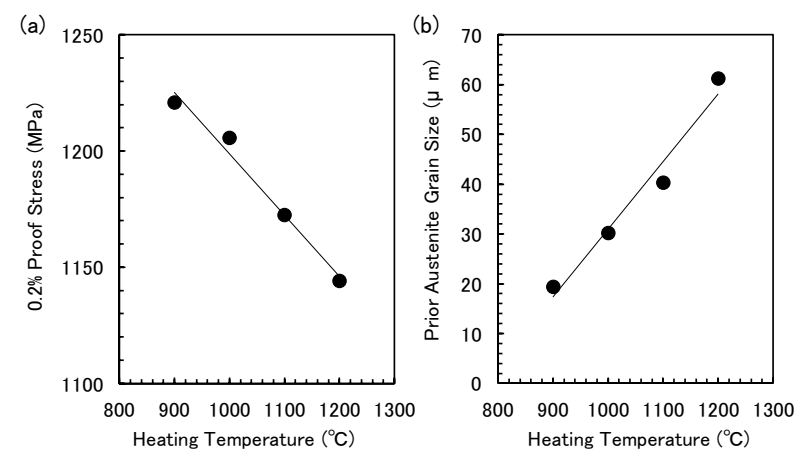

Figure 2. Effect of heating temperature on (a) $0.2 \%$ proof stress and (b) prior austenite grain size in the steel sheets cooled at $2330^{\circ} \mathrm{C} / \mathrm{s}$.

\subsection{Cooling rate}

The effect of secondary cooling rate on $0.2 \%$ proof stress is shown in Figure 3(a). With an increase in secondary cooling rate, the $0.2 \%$ proof stress increased. The effects of secondary cooling rate on dislocation density and amount of solute carbon are shown in Figure 3(b). With an increase in secondary cooling rate, dislocation density and amount of solute carbon increased. 

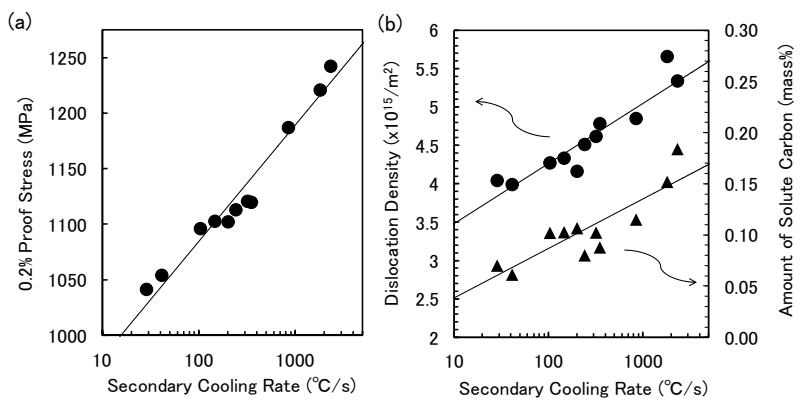

Figure 3. Effect of secondary cooling rate on (a) $0.2 \%$ proof stress, (b) dislocation density and amount of solute carbon.

Transmission electron photomicrographs of carbide in the steel sheets cooled at variable secondary cooling rate is shown in Figure 4. With a decrease in secondary cooling rate, the carbide was coarsened.

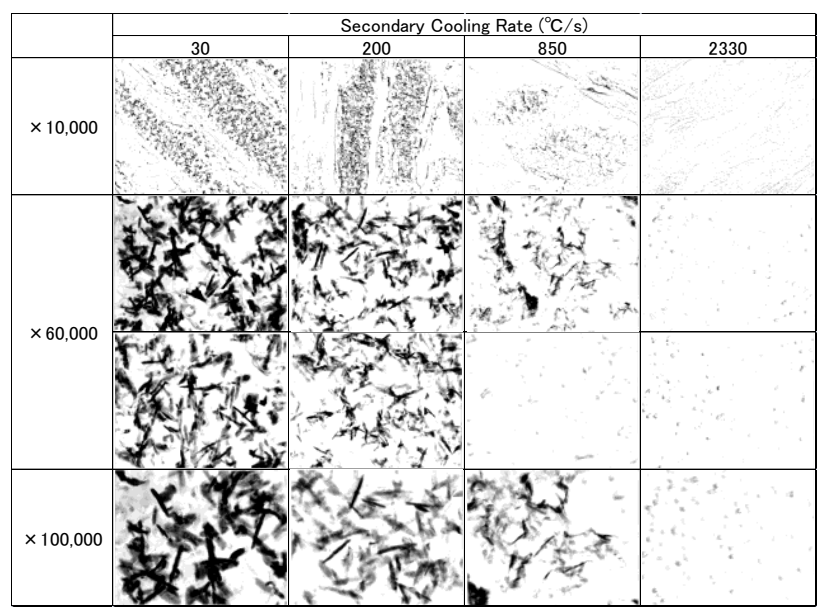

Figure 4. Transmission electron photomicrograph of carbide in the steel sheets cooled at variable secondary cooling rate.

In contrast, volume fraction of retained austenite decreased with an increase in secondary cooling rate as shown in Figure 5. Scanning electron photomicrograph of image quality and austenite mapping with EBSD in the steel sheets cooled at $30^{\circ} \mathrm{C} / \mathrm{s}$ below Ms are shown in Figure 6 . The austenite retained at lath or block boundaries. The area ratio of austenite is $2 \%$ and nearly equal to the volume fraction with X-ray diffraction.

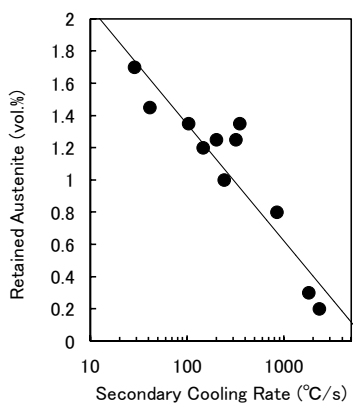

Figure 5. Effect of secondary cooling rate on volume fraction of retained austenite.

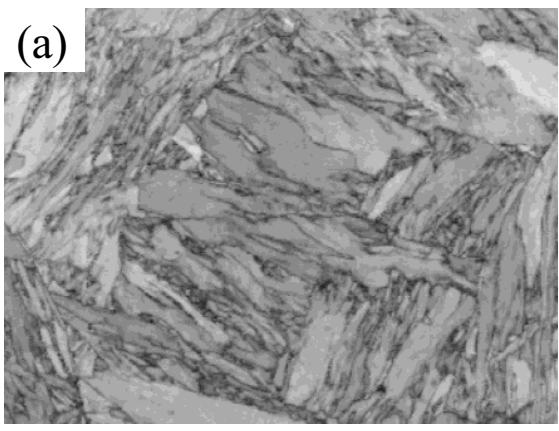

(b)

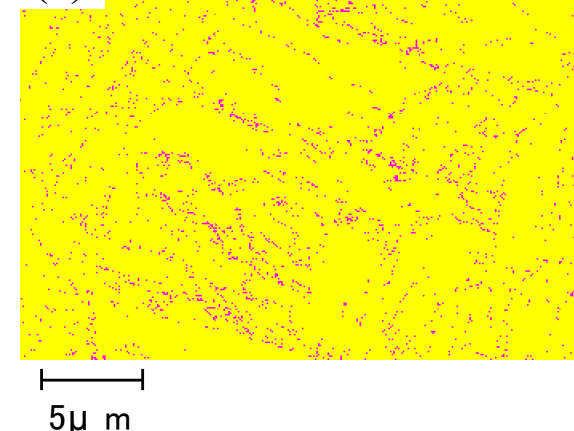

Figure 6. Scanning electron photomicrograph of (a) image quality and (b) austenite mapping with EBSD in the steel sheet cooled at $30{ }^{\circ} \mathrm{C} / \mathrm{s}$ below $400{ }^{\circ} \mathrm{C}$.

\subsection{Subzero treatment}

The effect of subzero temperature on retained austenite and $0.2 \%$ proof stress is shown in Figure 7 . By subzero treatment, the retained austenite decreased and $0.2 \%$ proof stress increased. There was little change in other microstructures after subzero treatment.
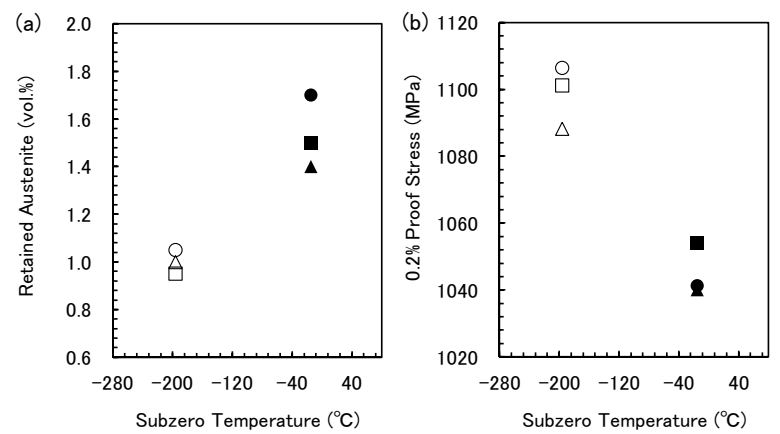

Figure 7. Effects of subzero temperature on (a) volume fraction of retained austenite and (b) $0.2 \%$ proof stress in the steel sheets cooled at $30{ }^{\circ} \mathrm{C} / \mathrm{s}$ below $400{ }^{\circ} \mathrm{C}$.

\section{Discussion}

We discuss the effect of microstructural factors on the $0.2 \%$ proof stress. The microstructural factors $0.2 \%$ proof stress are packet size, dislocation density, amount of solute carbon, carbide, and retained austenite.

\subsection{Effect of packet size}


Figure 8 shows the Hall-Petch-type plot analyzed in terms with packet size. The packet size was calculated on the basis of the linear relationship between the packet size and the prior austenite grain size $[3,4]$. These data was in good agreement with previous studies [4].

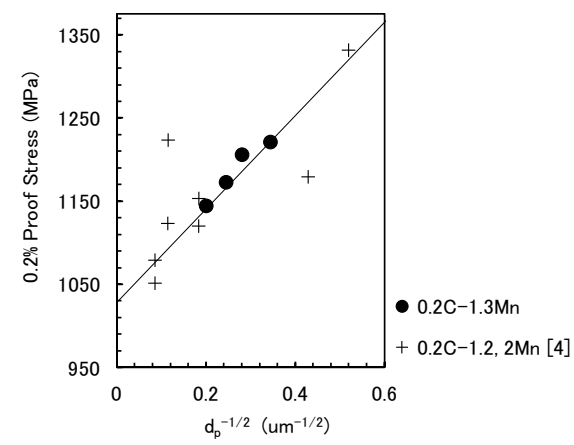

Figure 8. Hall-Petch plot relationship between reciprocal square root of the packet size and $0.2 \%$ proof stress.

\subsection{Effect of dislocation density, amount of solute carbon, and retained austenite}

Figure 9(a) shows the effect of dislocation density $(\rho)$ on $0.2 \%$ proof stress $\left(\sigma_{0.2}\right)$. Those results were an extension of the previous Bailey-Hirsch relationship [23, 24]:

$$
\sigma_{0.2}=\alpha \mathrm{Gb} \rho^{1 / 2}+\sigma_{0}
$$

where $\alpha$ is constant depending on dislocation tension, $\mathrm{G}$ is modulus of rigidity: $80,000 \mathrm{~N} / \mathrm{mm}^{2}$. The $\alpha \mathrm{Gb}$ was $1.6 \times$ $10^{10} \mathrm{MPa}^{*} \mathrm{~m}$. Figure 9(a) shows the effects of amount of solute carbon $\left(C_{\mathrm{s}}\right)$ on $\sigma_{0.2}$. Those data can be fitted with Fleisher's law as follows:

$$
\sigma_{0.2}=4 \beta \mathrm{G} \theta^{3 / 2} C_{\mathrm{s}}^{1 / 2}+\sigma_{0}
$$

where $\beta$ is constant depending on dislocation tension. The $4 \beta \mathrm{G} \theta^{3 / 2}$ is $1.7 \times 10^{3} \mathrm{MPa}^{*} \operatorname{mass} \%{ }^{2}$. This slope was nearly same with previous $\mathrm{Fe}-\mathrm{C}-\mathrm{Mn}$ data [25].

Figure 9(b) shows the effects of volume fraction of retained austenite, $V_{\gamma}$, on $\sigma_{0.2}$. The effect of $V_{\gamma}$ can be approximated by the negative-linear relationship as follows:

$$
\sigma_{0.2}=-\mathrm{k}_{\gamma} V_{\gamma}+\sigma_{0}
$$

where $\mathrm{k}_{\gamma}$ is $120 \mathrm{MPa} / \%$.
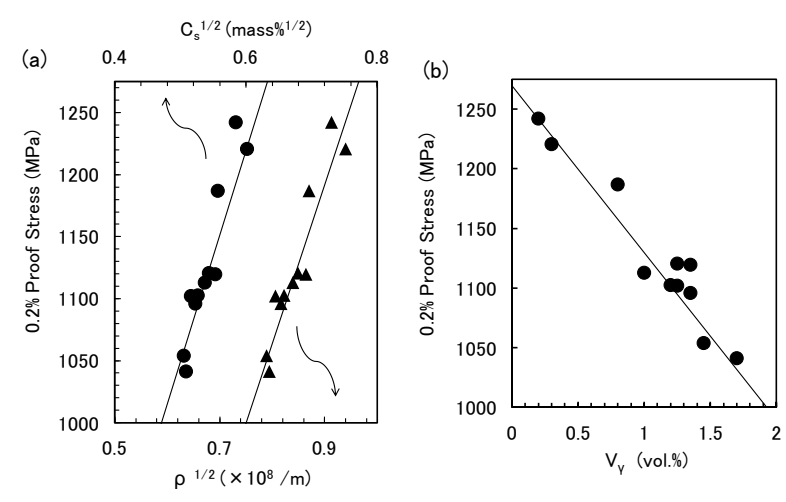

Figure 9. Effect of (a) dislocation density, solute carbon and (b) retained austenite on $0.2 \%$ proof stress.

As shown in Figure 10(a), the effect of retained austenite can be extracted by subzero treatment. Since there was little change in other microstructural factors, the effect of $V_{\gamma}$ appears to be negative-linear. As shown in Figure 10(b), retained austenite began to transform below $0.2 \%$ plastic strain. The stress-induced transformation of unstable austenite has a relatively large effect on the decrease in $0.2 \%$ proof stress.
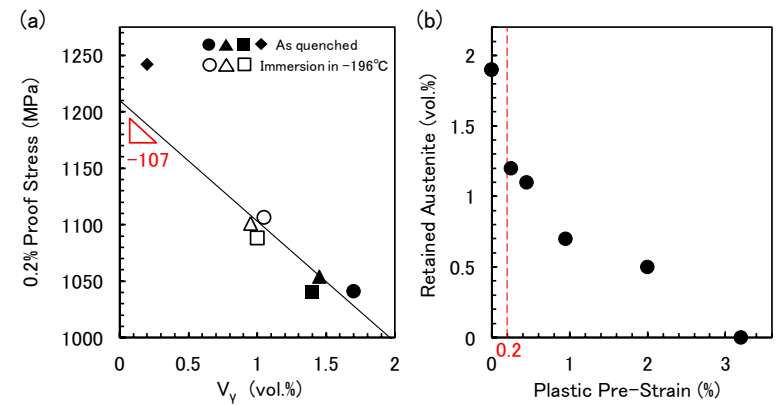

Figure 10. Effect of (a) subzero treatment on retained austenite and $0.2 \%$ proof stress and (b) plastic pre-strain on retained austenite.

\subsection{Estimation of microstructural contributions to strengthening}

The microstructural factors that affect $0.2 \%$ proof stress are packet size, dislocation density, amount of solute carbon, carbide, and retained austenite. Figure 11 shows the schematic representation of these effects. There was trade-off between the effect of solute carbon and carbide. Therefore, the summation of the effects of the factors, solute carbon and carbide, on $0.2 \%$ proof stress is expected to be constant. When all these contributions can be linearly added, the following expression will be suggested for the yield strength of the auto-tempered lath martensitic steel sheet.

$$
\sigma_{0.2}=\sigma_{0}+\mathrm{k}_{\mathrm{p}} d_{p}^{-1 / 2}+\alpha \mathrm{Gb} \rho^{1 / 2}-\mathrm{k}_{\gamma} V_{\gamma}
$$

The result of multiple regression analysis is following equation, and each maximum contribution is shown in 
Table 1. As far as the present experiment is concerned, the retained austenite is the most effective factor on the yield strength.

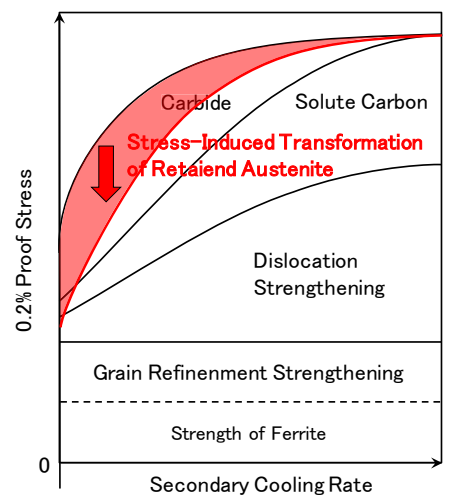

Figure 11. Schematic representation on the effect of strengthening mechanism by secondary cooling rate.

Table 1. Changes of microstructural factors and the range of variable $0.2 \%$ proof stress.

\begin{tabular}{|c|c|c|c|c|}
\hline \multicolumn{2}{|c|}{ Microstructural factor } & $\begin{array}{c}\text { Strengthening } \\
\text { mechanism }\end{array}$ & $\begin{array}{c}\text { Minimum and } \\
\text { maximum values }\end{array}$ & $\begin{array}{c}\text { Range of variable } \\
0.2 \% \text { proof stress (MPa) }\end{array}$ \\
\hline Packet & $\mathrm{d}_{\mathrm{p}}(\mu \mathrm{m})$ & $\begin{array}{c}\text { fine-grain } \\
\text { strengthening }\end{array}$ & $8.4 \sim 24.9$ & 110 \\
\hline Dislocation & $\rho\left(10^{15} \mathrm{~m}^{-2}\right)$ & $\begin{array}{c}\text { dislocation } \\
\text { strengthening }\end{array}$ & $3.9 \sim 5.6$ & 84 \\
\hline Retained austenite & $\mathrm{V}_{\gamma}(\mathrm{vol} \%)$ & $\begin{array}{c}\text { weakening with } \\
\text { transformation }\end{array}$ & $0.1 \sim 1.7$ & -128 \\
\hline \multicolumn{2}{|c|}{ Solute Carbon } & $\begin{array}{c}\text { Solute } \\
\text { strengthening }\end{array}$ & - & - \\
\hline \multicolumn{2}{|c|}{ Carbide } & $\begin{array}{c}\text { dispersion } \\
\text { strengthening }\end{array}$ & - & - \\
\hline
\end{tabular}

\section{Conclusion}

To clarify the dominant factor affecting the yield strength of auto-tempered lath martensitic steel, investigation of possible microstructural factors, grain, dislocation, solute carbon, carbide, and retained austenite were conducted with specimens, and were heated and cooled at various temperatures. As a result, the following expression was suggested for the yield strength of the lath martensite and the retained austenite is the most effective factor on the yield strength.

$$
\sigma_{0.2}=\sigma_{0}+769 d_{\mathrm{p}}^{-1 / 2}+6.9 \times 10^{15} \times \rho^{1 / 2}-80 V_{\gamma}
$$

6. S. Morito, et al. : Acta Materialia, 51(2003), 1789.

7. G. Thomas: Mtall. Trans, 2(1971), 2373.

8. G. Y. Lai et al.: Metall. Trans, 5(1974), 1663.

9. M. Yaso et al.: Mat. Trans, 50(2009), 275.

10. S. Morito, et al.: ISIJ International, 51(2011), 1200.

11. M. Cohen: Trans. Metal. Soc. AIME, 224(1962), 638.

12. G. Krauss: Materials. Sci. Eng., A273-275(1999), 40.

13. P. G. Winchell: Trans. ASM, 55(1962), 347.

14. M. J. Roberts: Trans. ASM, 60(1967), 687.

15. R. H. Aborn: Trans. ASM, 47(1956), 51.

16. G. R. Speich: Trans. Metall. Soc. AIME, 245(1969), 2553.

17. M. K. Miller, et al. : Metall. Trans. A, 12A(1981), 1197.

18. T. Nishibata, et al.: CAMP-ISIJ, 23(2010), 1226.

19. T. Nishibata, et al. : Tetsu-to-Hagané, 96(2010), 378.

20. G. K. Williamson and R. E. Smallman:Philos. Mag., 8(1956), 34.

21. G. K. Williamson and W. H. Hall : Acta Metall., 1(1953), 22.

22. L. Xiao, et al.: Phys. Rev. B, 52(1995), 9970.

23. J. E. Bailey and P. B. Hirsch:Philos. Mag., 5(1960), 485.

24. K. Nakashima, et al. : Tetsu-to-Hagané, 93(2007), 459.

25. L.-A. Norstrom: Scan. J. Metall., 5(1976), 159.

\section{References}

1. M. J. Roberts : Metall. Trans., 1(1970), 3287.

2. T. Swarr and G. Krauss : Metall. Trans. A, 7A(1976), 41.

3. T. Maki, K. Tsuzaki, and I. Tamura.: Transactions ISIJ, 20(1980), 207.

4. S. Morito, et al. : Mat. Sci. Eng. A, 438(2006), 237.

5. J. M. Marder and A. R. Marder:Trans. ASM, 62(1969), 1. 
